\title{
Humeanism, Best System Laws, and Emergence
}

\author{
Olivier Sartenaer
}

To appear in Philosophy of Science. Please cite the published version.

\begin{abstract}
To this day, debates on ontological emergence have been almost exclusively carried out within non-humean power-based or law-based metaphysics, the main underlying stake being indeed whether or not irreducible causal powers, or irreducible governing laws, can happen to come into being under specific circumstances. It is therefore unsurprising that humeanists themselves never felt that attracted by emergence, consistently with Lewis' own dismissal of "suchlike rubbish".

In the present paper, I argue, contrary to this received wisdom, that humeanism and ontological emergence can actually peacefully coexist. Such a coexistence can be established by reviving some elements of John Stuart Mill's philosophy of science, in which a very idiosyncratic account of diachronic, evolutionary emergence is associated with extensions of the humean mosaic and the correlative coming into being of new best system laws, which have the peculiarity of being temporally indexed. Incidentally, this reconciliation of humeanism and emergence allows for conceiving the autonomy of the special sciences in an interesting way, consistently with the reductionist ideal of a unified, all-encompassing science.
\end{abstract}

\section{Keywords}

Humeanism - Best System Account - Lawhood - Emergence - Diachronic emergence - Special sciences - Unity of science

\section{Acknowledgments}

XXX 


\section{Introduction}

To this day, ontological emergence has been almost exclusively debated within non-humean power-based or law-based metaphysics. Typical discussions involve dispositional essentialists or nomic necessitarians, who would usually wonder about whether a case can be made that irreducible causal powers, or irreducible governing laws, can happen to come into being under some specific circumstances. Be they enamored with emergence or rather partisans of reductionism, participants generally share a basic common ground in some version of the Eleatic principle, according to which "to be is to have determinative power" (see e.g. Peacocke 2007; or Kim 1992 for a version restricted to causation). One of the main stakes of these debates concerns the nature of the relation that ought to exist between fundamental physical entities and non-fundamental natural entities, as well as, incidentally, the relation that ought to exist between physics and the socalled special sciences. In this respect, it is the ontological emergentists' recurrent contention that, whatever such relations ultimately are, special sciences' entities - be they objects, properties or laws - should somehow be "efficacious" (Wilson 2015) or "determinative" (Gillett 2016) in their own rights, to the effect that, granted emergence, the special sciences would be at least partly autonomous from the physical sciences.

That such debates have been overwhelmingly played out in a non-humean arena is no real surprise. For one thing, contemporary humeanists themselves never felt that attracted by emergence - consistently with Lewis' own dismissal of "suchlike rubbish" (1986, x) -, as it seems supervenience has always been all they really needed. But it is also certainly true that, at least until recently, most of the ontological emergentists out there happened to pursue a personal agenda - e.g. vindicating irreducible agent causation in a libertarian setting (Lowe 2008) or arguing that social structures have irreducible causal powers (Elder-Vass 2010) -, for which, this is sure, humeanism is of no help. As things stand, the humeanists' systematic repudiation of necessary connexions appears to be frontally at odds with the widespread recognition that, typically, ontological emergents are supposed to come with a decent measure of modal force.

Yet, notwithstanding Tooley-style arguments to the effect that the putative existence of yet-uninstantiated emergent properties should undermine regularity theories (Tooley 1977; Armstrong 1983, chap. 8) - arguments which, I think, have been properly debunked (Beebee 2000) -, advocating the irreducibility of some worldly entities and, with it, the possible autonomy of some special sciences, doesn't prima facie appear to be an endeavor 
that ought not to be pursued in a humean setting. What appears as a good indication that such a claim is not totally unreasonable certainly is the fact that, at present, it is rather standard to trace the very birth of emergentism in the works of a philosopher, John Stuart Mill, who also happened to embrace a broadly humean worldview (Stephan 1992).

Unfortunately, although Mill is usually seen as the main progenitor of emergence, there hasn't been many attempts to exactly explicate the way in which he construed the notion. As a result, Mill's view is often unapologetically conflated with other distinct accounts of emergence under the unfortunate umbrella label of "British Emergentism"1. However, as I will endeavor to show in this paper, Mill's view on emergence turns out to be rather idiosyncratic, and actually provides us with some unexpected resources that allow, pace Lewis, for somehow reconciling humeanism with (ontological) emergence.

Digging out Mill's philosophy of emergence and emphasizing the extent to which it happens to conflict with its standard contemporary interpretation can certainly have some historical interest, but it is not what will primarily keep me busy here. The main purpose of the present paper is rather to use Mill's scattered insights on emergence as guides towards the establishment of a peaceful coexistence between humeanism and emergence. As a secondary objective, I also show that some peculiar form of ontological emergence allows for conceiving the autonomy of the special sciences in an interesting way, consistently with the reductionist ideal of a unified, all-encompassing science. Incidentally, in a companion paper to come, such a conception will be claimed to strengthen a recent variant of the humean Best System Account of lawhood, known as the "Better Best System Account" [BBSA] (Schrenk 2008; Cohen \& Callender 2009), for which, it has been contented, John Stuart Mill is to be considered the "patron saint" (incidentally warranting the claim that, in a certain sense, humeanism isn't necessarily hostile to emergentism; Schrenk 2017).

Here is how the discussion is going to be structured. In section 2, I first describe the main tenets that define Mill's broadly humean worldview and, more particularly, his specific take on lawhood. In section 3, I introduce Mill's notorious distinction between "homopathic" and "heteropathic" combinations of causes and laws, on which the current "resultant/emergent"

\footnotetext{
${ }^{1}$ Although McLaughlin (1992)'s important contribution to the study of the history of emergentism is respectful to the diversity of the different views that participated to such an emergentism, the convenient label of "British emergentism" that he coined has been subsequently used with the implicit and detrimental suggestion that all the emergentists involved - from Mill to Broad - were sharing one and the same construal of emergence.
} 
distinction is usually considered to collapse. I then proceed by extracting the ontological consequences of the putative existence in nature of heteropathic effects and laws, by showing that they are to be related to extensions of the humean mosaic (section 4) and, with it, a conception of ultimate laws as being temporally indexed (section 5). On this basis, I propose a synthetical and evolutionary reconstruction of Mill's view on the "growing humean mosaic" and the way it gives rise to a unified science, somewhat paradoxically made of autonomous special sciences (section 6). I close this paper by proposing semi-formal definitions of Mill's emergence that allow to localize it in the very diverse, contemporary conceptual landscape of the notion (section 7 ).

Before getting started, a note of caution is needed. It is notoriously difficult to exactly pin down Mill's ontological commitments - most of which being broadly humean while some having rather elusive realistic tones -, as he himself investigated the logic of science rather than its underlying metaphysics. In this respect, the reconstructions found in this paper are by no means meant as thorough scholarly exegeses of Mill's philosophy of science. More modestly, I merely propose a plausible picture of the reconciliation between humeanism and emergence that is consistent with Mill's view, filling the gaps, when necessary, in ways that are as charitable as possible.

\section{Lawhood in humeanism}

For the purpose of the present paper, it is enough to delineate Mill's broadly humean worldview with the help of the three following features ${ }^{2}$ :

\footnotetext{
${ }^{2}$ I take events (understood as property instances) to be the units of the humean mosaic as well as the relata of causal relations and laws. This choice is certainly conventional, and is partly motivated by a willingness to render Mill's view on lawhood commensurate with subsequent discussions on emergence. Also, it should be emphasized from the outset that humeanism is here understood in a broader, less restricted sense than typical Lewisian humeanism. In particular - and as we'll see -, nothing in humeanism itself should prima facie force us to adopt a counterfactual analysis of causation, an eternalist theory of time or a physicalist ontology. Finally, although endorsements of the regularity views of laws and causation aren't difficult to spot in Mill's works, bringing to light his commitment to humean supervenience is certainly more indirect. This can actually be achieved by stressing Comte's notorious influence on Mill, whose very philosophical project was to render science "positive". Such an endeavor notably required getting rid of obscure ideas as "forces", which simply are the relic of the metaphysical age of science, when godly, extra-natural influences, hallmarks of the previous and bygone theological age, have been materialized. And it turns out that it is precisely because forces are so rejected that all there is left are humean patterns of events (Millgram 2009).
} 
- Humean supervenience [HS] - The world is some sort of a vast mosaic of property instances localized at spatio-temporal points. Everything else that is not immediately part of such a mosaic supervenes on it. The property instances composing the mosaic are taken to be (i) fundamental and (ii) non-modal, to the effect that (i) every natural property instance only obtains in virtue of the instantiation of some of these fundamental properties, and (ii) no property instance that belongs to the mosaic is modally connected to other property instances.

- Regularity view of laws [RVL] - Laws do not govern the succession of particular events of the mosaic. Rather, and in accordance with [HS], they simply are patterns or regularities (of a special sort) among them. Lawful regularities are described by law statements, which figure in scientific theories.

- Regularity view of causation [RVC] - Causation is not productive. It is rather a relation of constant conjunction between discrete events of the mosaic. Consistently with [HS] and as with [RVL], there is no (natural) modality in such relation. Causation just is the regular succession in time of particular events ${ }^{3}$.

With respect to [RVL], the very fact that a distinction can be made between laws (of nature) and law statements is indicative of a realist facet of Mill's philosophy of science, according to which science is in the business of revealing the way the world essentially is (Macleod 2017). Mill himself acknowledges the possible confusion that follows from this: "[T]he expression, Laws of nature, means nothing but the uniformities which exist among natural phenomena [...]" (1884, 208, italics in the original), yet "[i]t is the custom of science [...] to call the general proposition which expresses the nature of that regularity a law [...]" $(1884,207)$.

\footnotetext{
${ }^{3}$ True, it has been claimed that Mill's view on causation may be taken to be in line with metaphysical frameworks that posit powers or capacities in nature (Cartwright 1989), an exegesis often substantiated by Mill's own contention that "[t]hese facts are correctly indicated by the expression tendency. All laws of causation, in consequence of their liability to be counteracted, require to be stated in words affirmative of tendencies only, and not of actual results" (1884, 293; italics in the original). Yet, I think that such a reconstruction has been properly debunked (Schmidt-Petri 2008), Mill using the term "tendency" for methodological rather than metaphysical reasons, only in those situations where it makes sense to talk about causes that are impeded by other causes. As things stand, Mill can even be considered to have offered a sophisticated version of [RVC] (Psillos 2002).
} 
Now, the orthodoxy has it that Mill is the pioneering proponent of a particular variant of [RVL] - although with the slight realistic tone just mentioned -, namely the so-called "Mill-Ramsey-Lewis" or Best System Account [BSA] of lawhood (Earman 1986). Among other features, such an account provides a principled way of distinguishing between those regularities that appear to be merely accidental, and which are accordingly to be captured by accidentally true generalizations, from those regularities that turn out to be genuinely nomic and, as such, describable by law statements. Such a distinction can in principle be drawn through the running of some kind of competition between all the available deductive systems that concern the property instances composing the humean mosaic, and of which the theorems are true. It is the [BSA]'s main contention that the laws just are the axioms and the theorems of the one system that achieves the best balance between two virtues that generally tend to work against one another, namely strength - a measure of informativeness - and simplicity - a measure of the sobriety of systematization.

Still, in Mill's own view (1884, 206-207), referring to the axioms and the theorems of such a best system as "laws" amounts to a "lax application" of the term. A stricter application would be to consider as laws only those regularities that are "distinct" and "independent", such that, when they are taken for granted, "the others follow" or "result from them". Put differently, Mill is actually considering two different kinds of law: (i) the genuine ones, which are the invariant and unconditional regularities that obtain among the fundamental property instances of the humean mosaic, and which are to be captured by law statements that are the axioms of the best deductive system that is true to the mosaic, and (ii) the derivative ones, which are regularities that obtain in virtue of those fundamental regularities, and that are describable by law statements that are deducible from the axioms, that is, by the theorems of the best system. For the sake of simplicity, and bearing in mind that, according to Mill, only the former are to be considered as the laws - coherently with the claim that the laws are "the fewest general propositions from which all the uniformities which exist in the universe might be deductively inferred" $(1884,207)$-, I'll keep referring in what follows to the distinction between the laws captured by the axioms and the theorems as, respectively, the "ultimate" (or fundamental) laws versus the "derivative" (or non-fundamental) laws.

This being said, it might prima facie appear that such an account of lawhood makes it difficult, if not impossible, to take seriously the very existence, yet alone the autonomy, of laws in the special sciences, insofar as such laws are supposed not to be directly about the fundamental property instances 
of the humean mosaic. As things stand, one can indeed have serious reasons to expect that, while running the competition between the available deductive systems that are true to the mosaic, the generalizations of the special sciences will at best invariably come out only as theorems of the winning system, that is, as mere derivative laws. However, Mill's philosophy of science presents a further resource that makes this judgment premature. It is indeed an idiosyncrasy of Mill's view that his version of the [BSA] - in sharp contrast with Lewis' - comes hand in hand with some non-trivial form of antireductionism, something one can only fully appreciate with an adequate account of Mill's emergence at hand.

\section{Combining causes and combining laws}

In the book on induction that is part of his System of Logic, Mill discusses what he takes to be "one of the fundamental distinctions in nature" (1884, 244 ), which is about two different modes of composition of causes or, equivalently, of mutual interference between laws. The first mode, referred to as "homopathic", is very general. It obtains as long as the Principle of the Composition of Causes [PCC] is satisfied, that is, as long as "the joint effect of several causes is identical with the sum of their separate effects" (1884, 243). [PCC] continuously obtains for phenomena studied by the science of mechanics. It is actually embodied in Newton's second law $\mathbf{F}=m \mathbf{a}$, where the resulting effect $\mathbf{a}$ of the joint action $\mathbf{F}$ of several causes $\mathbf{F}^{\mathbf{i}}$ is indeed always identical with the (vectorial) sum of the partial effects $\mathbf{a}^{\mathbf{i}}$ that each of these causes would have had in isolation. In corresponding nomological terms, the law about the joint cause and effect $\mathbf{F}=m \mathbf{a}$ is identical to each of the laws about the separate causes and effects $\mathbf{F}^{\mathbf{i}}=m \mathbf{a}^{\mathbf{i}}$, insofar as these do not "interfere" with one another while they combine.

According to Mill, it is an empirical, contingent matter of fact that $[\mathrm{PCC}]$ does exceptionally fail, to the effect that causes sometimes happen to combine, and laws happen to interfere, in a "heteropathic" way". In that kind of situation, which typically occurs on the occasion of chemical reactions, the joint effect of combined causes is not identical to the sum of the separate effects that these causes would have had on their own. As Mill puts it himself with respect to the synthesis of water from (di)hydrogen and (di)oxygen: "Not a trace of the properties of hydrogen or of oxygen is ob-

\footnotetext{
${ }^{4}$ It is George Henry Lewes who later renamed Mill's homopathic/heteropathic distinction into the "resultant/emergent" terminology more commonly used nowadays.
} 
servable in those of their compound, water" $(1884,243)^{5}$. In corresponding nomological terms, the law about the joint cause and effect is different from the laws about the separate causes and effects. Water can then be at play in nomic regularities that are "heterogeneous" with regard to any of the nomic regularities in which hydrogen and oxygen happen to find themselves at play.

This being said, one may wonder why it is the case that any failure of $[\mathrm{PCC}]$, that is, any heteropathic composition of cause, amounts to what one would be ready to consider as a non-trivial form of emergence. In a nutshell, this relies on two complementary observations. Each breach in $[\mathrm{PCC}]$ is the occasion of (i) an extension of the humean mosaic, that is, the advent of new fundamental property instances that belong to a new ontological domain, and (ii) the correlative advent of new ultimate laws that acts as bridgelaws between the old and the new domains. Let us now flesh out these observations in more detail.

\section{Emergence and the growing humean mosaic}

As a starting point, Fig. 1 provides a diagrammatical representation of the general, homopathic situation. Although it is true that Mill invariably speaks of causal composition in terms of addition, scalar or otherwise, one can easily generalize to any other kind of combinatorial relation, hence the neutral notation $R\left(x_{i}^{1}, x_{i}^{2}, x_{i}^{3}\right)^{6}$. The only thing that really matters is that, in the homopathic case, it is the same relation $R$ that holds for both the combinations of causes and effects. Indeed, it is only in this respect that the same laws obtain for both joint and separate causes and effects. In the light of the canonical mechanical illustration again, it is because both forces and acceleration combine in the same way, viz. additively, that we have that $\mathbf{F}=\sum \mathbf{F}^{\mathbf{i}}=m \sum \mathbf{a}^{\mathbf{i}}=m \mathbf{a}$. From this, it follows that it is always possible to anticipate the occurrence of any homopathic effect. From knowledge of [PCC], the laws $L^{k}\left[c_{i}^{k}, e_{j}^{k}\right]$ that are about the separate causes and effects as well as the relation $R$ in which the causes stand with respect to one another at time $t_{i}$, one can indeed predict the occurrence of $E_{j}$ at

\footnotetext{
${ }^{5}$ This kind of observation certainly is at the very root of the traditional association of emergence with the holist slogan according to which "the whole is more than the sum of its parts". Yet, as we'll see shortly, such an association can be misleading.

${ }^{6}$ For the sake of uniformity, I will continue using subscripts $i, j$ and $k$ as temporal indications, $x_{i}$ being the instantiation of $x$ at time $t_{i}$. Superscripts are mere identification labels. Expressions like $x^{n}$ are used to denote either the $n$-th $x$ or all possible $x^{i}$ (with $i$ being any integer from 1 to $n$ ), depending on the context.
} 
$t_{j}$. Equivalently, the law $L\left[C_{i}, E_{j}\right]$ is a derivative law. Accordingly, and to state the obvious, $E_{j}$ is not a fundamental property instance of the humean mosaic. Rather, it only obtains in virtue of the instantiation of the other fundamental property instances $e_{j}^{k}$ standing in relation $R$. $E_{j}$ is thus nothing "over and above" the instantiation of each $e_{j}^{k}$ standing in relation $R$. In contrast with the heteropathic case - and as we'll see shortly -, all the separate causes therefore "have their full effect" (Mill 1884, p. 243).

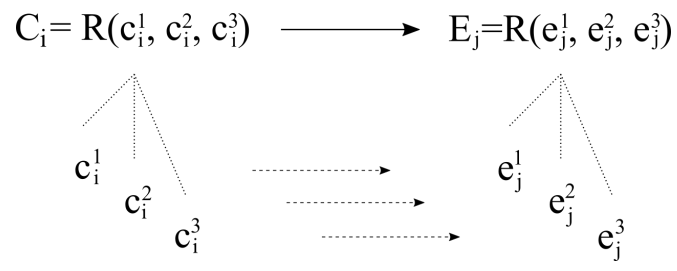

Figure 1: Homopathic composition of causes and effects.

Let's now turn to the emergent case, in which [PCC] breaks down, that is, in which the joint effect $E_{j}$ is not identical to the separate effects $e_{j}^{k}$ standing in relation $R$ (or, for that matter, in any relation $R^{*}$; see Fig. 2 ). In that kind of case - and this is the crux of the idiosyncrasy of Mill's emergence that is often overlooked -, the separate effects $e_{j}^{k}$ simply don't exist (at least in the spatio-temporal region of the phenomena under consideration), to the effect that an heteropathic combination of causes can be seen as a process during which some due effects unexpectedly give way to something utterly different. As Mill puts it himself (1884, 246): "At some particular points in the transition from separate to united action, the laws change, and an entirely new set of effects [...] take place of those which arise from the separate agency of the same causes"7. Accordingly, an heteropathic effect $E_{j}$ always is a new fundamental property instance of the humean mosaic, or,

\footnotetext{
${ }^{7}$ It is noteworthy that Mill also envisioned the possibility that the existence of the joint effect $E_{j}$ is "added to", instead of replacing, the one of the separate effects $e_{j}^{k}$. Because this possible variant has no impact on the facts that matter here, namely that $E_{j}$ is a new fundamental property instance of the humean mosaic and the corresponding heteropathic law is to be conceived of as ultimate, I don't explore this option further. Also, that laws might "change" or "interfere" with other laws should not be taken too literally, as this is not something that humean laws can do. More precisely, as we will see in section 5 , though individual laws don't change upon emergence, it is the case that the set of laws that best captures the humean mosaic happens to grow. Finally, that the separate effects $e_{j}^{k}$ aren't necessarily instantiated at time $t_{j}$ seems to be indicative of the fact that an essential condition of causation encapsulated in Mill's version of [RVC] breaks down, namely that causes must be followed by their effects "unconditionally" $(1884,222)$, to the
} 
to put it differently, it does not exist in virtue of anything else than itself. Neither does it exist in virtue of its cause $C_{i}$, given [RVC] and its underlying assumption that, so to speak, no cause contains the seed of - or produces its effect. Nor does it exist in virtue of - or, nor does is supervene on the separate effects $e_{j}^{k}$, for these are generally not co-instantiated. True, the very fact that an heteropathic effect $E_{j}$ is not grounded in putatively more fundamental property instances doesn't prevent it from being instantiated in systems whose formation depends in some sense on a previous constellation of conditions. Although in Mill's empiricist perpective the liquidity of water is genuinely heterogeneous from the gaseous nature of hydrogen and oxygen - to the effect that one couldn't recognize the relevant traces of the later in the former -, it is indeed still the case that liquid water is what regularly proceeds from a transformation of hydrogen and oxygen in the appropriate conditions. The apparent air of contradiction here is typical of emergentism, which generally requires one to be committed to the somewhat paradoxical idea that emergent property instances can at the same time be dependent (on what constitutes their emergence bases) and fundamental ${ }^{8}$.

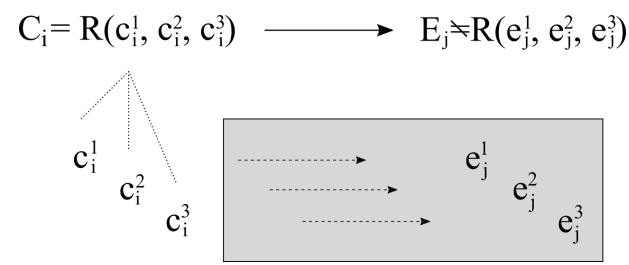

Figure 2: Heteropathic composition of causes and effects. The shaded region is non-occurrent, to the effect that $E_{j}$ cannot be any relation $R^{*}$ - and, in particular, $R$ - of the $e_{j}^{k}$.

It follows that every instance of Mill's emergence is the occasion of an extension of the humean mosaic. Under Mill's view, the mosaic happens to grow through time, as new semi-autonomous domains of fundamental emergent property instances are frequently added to the whole picture. As we'll see in what follows, each of these extensions of the mosaic corresponds to the advent of a new domain that is definable of a special science.

effect that one may wonder whether heteropathic causes are to be considered causes at all. A possible way out of this problem seems to have been envisioned by Mill himself, who suggested that heteropathic cases should be construed as "transformational" rather than causal stricto sensu, on the model of water being the product of a transformation of hydrogen and oxygen (e.g. 1884, 290-291; see also section 7). I thank Paul Humphreys and an anonymous reviewer for having brought my attention on this.

${ }^{8}$ On this general point, see Barnes (2012). 


\section{Temporally indexed laws and the autonomy of the special sciences}

Given [HS] and [RVL], it follows from each extension of the humean mosaic that new laws are needed to systematize each new domain and its constitutive fundamental property instances. It is indeed the main initial underlying assumption of the heteropathic mode of interference between laws that, upon emergence, laws of nature, "when called upon to work together, cease and give place to others" $(1884,244)$. Such new laws, actually $L\left(C_{i}, E_{j}\right)$ in the simplified case depicted on Fig. 2, are to be considered ultimate, in the sense that they cannot be deduced from any combination of other laws (in particular, the laws $L^{k}\left[c_{i}^{k}, e_{j}^{k}\right]$, even together with [PCC] and knowledge of how the separate causes $c_{i}^{k}$ happen to be related). As a result, the occurrence of every emergent property instance $E_{j}$ is theoretically unpredictable, despite the fact that, given Mill's commitment to determinism $(1884,201)$, it can of course be inductively predicted as soon as $L\left(C_{i}, E_{j}\right)$ has come to be known as the outcome of an adequate experiment. Mill's emergence therefore comes with the contention that all of science's first principles are not "first" at all, at least in a temporal or historical sense. Rather, ultimate laws turn out to be temporally indexed. They all have a starting date, so to speak, which doesn't necessarily correspond to the date the world begun (if it ever begun on some specified date) ${ }^{9}$.

Mill's growing view of the humean mosaic and the laws that come with it has an important impact on the very structuring of science itself. It indeed turns out that any true deductive system of law statements, which achieves the best combination of strength and simplicity at some given time $t_{i}$, becomes immediately obsolete as soon as some breach in [PCC] occurs, insofar as, then, it immediately loses strength by being unable to accommodate the new extension of the mosaic. As a result, one has to run the competition afresh with respect to the newly extended mosaic.

To understand what the result of such new competition has to be, two preliminary remarks are in order. First, in Mill's view, it is of course possible for heteropathic laws to combine homopathically (or for heteropathic effects to subsequently combine as homopathic causes of further effects). As a

\footnotetext{
${ }^{9}$ Obviously, this strongly departs from Lewis' version of the [BSA]. In Mill's broadly empiricist worldview, there is no sense in claiming that heteropathic laws do exist before the corresponding breach in [PCC], even as uninstantiated laws, for then (i) the fundamental property instances on which these laws supervene do not exist, and (ii) these laws are impossible to know in principle (be it by induction or deduction). For more detail on Mill's [BSA] in relation with temporality, see section 6 .
} 
result, once a new domain of events $D_{i}$ has emerged, these events generally combine in such a way as their joint effects also belong to $D_{i}$. Accordingly, each domain has its own regularities. Some of them are ultimate, in the sense of being about the fundamental property instances of that domain, and the others are derivative, as they only obtain in virtue of a homopathic combination of these fundamental property instances. As it turns out, an intra-domain competition can then be run independently for every domain $D_{i}$, the result of which being the deductive system that best systematizes the events of $D_{i}$. Such a system has the ultimate and the derivative laws of $D_{i}$ as its axioms and its theorems, respectively, and is constitutive of a freestanding special science ${ }^{10}$. In Mill's own words, with $D_{i}$ being the chemical or the physiological domain $(1884,245)$ :

"[T]here is no reason to despair of ultimately raising chemistry and physiology to the condition of deductive sciences; for though it is impossible to deduce all chemical and physiological truths from the laws or properties of simple substances or elementary agents, they may possibly be deducible from laws which commence when these elementary agents are brought together into some moderate number of not very complex combinations. The Laws of Life will never be deducible from the mere laws of the ingredients, but the prodigiously complex Facts of Life may all be deducible from comparatively simple laws of life [...]."

That brings us to the second remark. Mill's way of talking sometimes erroneously suggests that heteropathic laws can contravene previous laws ${ }^{11}$. Of course, literally, that cannot be the case. Consistently with [RVL], once an event is not obtaining, as in the case of the separate effects $e_{j}^{k}$ in an heteropathic situation, there simply is no law "out there" that is prevented from "acting", as humean laws only supervene on occurrent events. Accordingly, laws that belong to a domain $D_{i-1}$ remain laws of that domain, even after a domain $D_{i}$ and its own laws have emerged therefrom. In particular,

\footnotetext{
${ }^{10}$ For a similar idea, see Schrenk 2017. Mill can here be seen as promoting an ontological variant of Cohen and Callender (2009)'s essentially perspectival version of the [BBSA], where the boundaries of the domains in which competitions have to be run are fixed by way of stipulation.

${ }^{11}$ But he also sometimes clearly indicates that this is not the case, as when he claims that "[t]hose bodies [parts of a vegetable or animal substance] continue, as before, to obey mechanical and chemical laws, in so far as the operation of those laws is not counteracted by the new laws which govern them as organized beings" (1884 245). Note that, given $[\mathrm{RVL}]$, the use of expressions like "obey" and "govern" is certainly unfortunate here.
} 
neither "overlaps" nor "conflicts" are expected to occur between the laws of these domains, insofar as, by definition, they are regularities among different fundamental property instances of the growing humean mosaic. This is not a trivial point, as it is this very ingredient of Mill's take on emergence that allows for science to remain a unified endeavor, despite the existence, within it, of several quasi-autonomous special sciences, each having its own best deductive system that is true to its own domain. As such, a separate, inter-domain competition can then also be run, which will designate the best deductive system for all domains of events existing at time $t_{i}$. This system will invariably contain, as axioms, all the axioms of the first domain-specific best system $-D_{1}$ or physics - together with all the heteropathic laws that have appeared upon each and every breach in [PCC] before $t_{i}$, and which act as inter-domain ultimate bridge-laws. In this spirit, with respect to the unification of physics and chemistry, Mill contends that (1884 246):

"[I]n chemistry, these undiscovered laws [the heteropathic laws] of the dependence of the properties of the compound on the properties of its elements, may, together with the laws of the elements themselves, furnish the premises by which the science is perhaps destined one day to be rendered deductive".

\section{The dynamical unity of science}

Fig. 3 and 4 summarize the upshot of the discussion so far. They can both be seen as representing an emergent evolution of some sort, of which the relevant steps can be described as follows.

At the very origin of the world - whenever that may be, let's say at $t_{1}-$, there was nothing but physical events that combined homopathically, to the effect that the best deductive system $D_{1}^{*}$ that was true to the only domain $D_{1}$ of the mosaic only contained, as axioms, the ultimate laws of physics (as humean laws, these laws span the whole temporal extension of $D_{1}$, from $t_{1}$ onwards until the end of time). At some later time $t_{2}$, a first breach in $[\mathrm{PCC}]$ occurred, and a new domain $D_{2}$ of fundamental property instances - those of chemistry - emerged. Although $D_{1}^{*}$ then remained the best deductive system available for $D_{1}$ - for no law was to be contravened upon the breach in $[\mathrm{PCC}]-$, it failed to appropriately systematize the events of $D_{2}$, and hence could not qualify as the best system for the mosaic at $t_{2}$, that is, $D_{1} \cup D_{2}$. Two new competitions were then to be run. Building on the fact that chemical events also generally combined among themselves homopathically, the first competition, internal to $D_{2}$, designated $D_{2}^{*}$ as the 


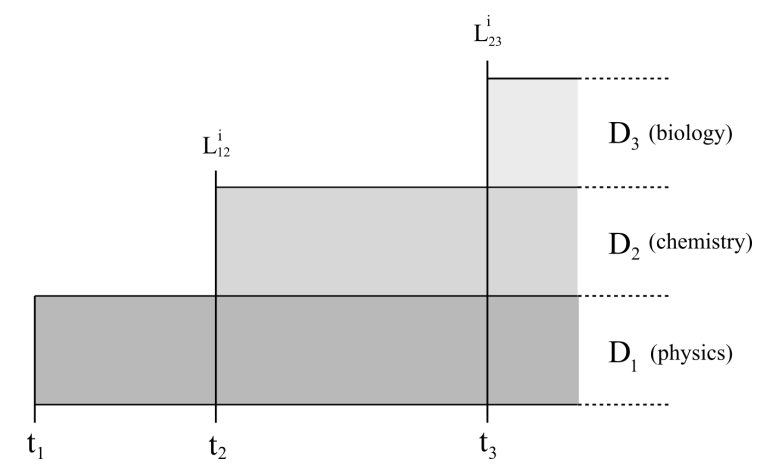

Figure 3: Mill's growing humean mosaic, where new quasi-autonomous domains of events $D_{i}$ keep stacking on one another upon each breach in [PCC]. Emergence is here what accounts for the existence of the various special sciences.

best system for $D_{2}$, making chemistry a deductive science with its own axioms and theorems (again, the corresponding laws span the whole temporal extension of $D_{2}$, from $t_{2}$ onwards until the end of time). With respect to a second competition, this time run against $D_{1} \cup D_{2}$, the best deductive system that came out was the one that had, as axioms, the axioms of $D_{1}^{*}$ together will the inter-domain, heteropathic laws $L_{12}^{i}$ (of the form $L^{i}(C, E$ ), with $C$ and $E$ belonging to $D_{1}$ and $D_{2}$, respectively). The story then kept repeating itself relative to the advent of the other domains of the mosaic and their corresponding special sciences, predicated on the further assumptions that the biological domain $\left(D_{3}\right)$ emerged from the chemical domain $\left(D_{2}\right)$, the psychological domain $\left(D_{4}\right)$ emerged from the biological domain $\left(D_{3}\right)$, etc. At the end of time, the whole of science is in principle to be rendered fully deductive. The final best system $\mathcal{D}^{*}$ will have, as axioms, the axioms of physics together with all the heteropathic laws which obtained on the occasion of each and every breach in $[\mathrm{PCC}]$ that occurred throughout history.

It is clear from such discussion that Mill's version of the [BSA] essentially differs from Lewis', in that the former considers the supervenience basis of any law of nature to be temporally restricted to a given time interval $\left[t_{i}, \infty\right]$, while for the later it invariably consists of the whole history of the universe (so that $t_{i}$ is always arbitrarily set to zero). Restricting, as Mill does, the period over which some nomic regularities obtain and, accordingly, some best system prevails, isn't prima facie inconsistent, even if it can strike as strongly counter-intuitive. As Lange recently put it (2008, 88-89): 


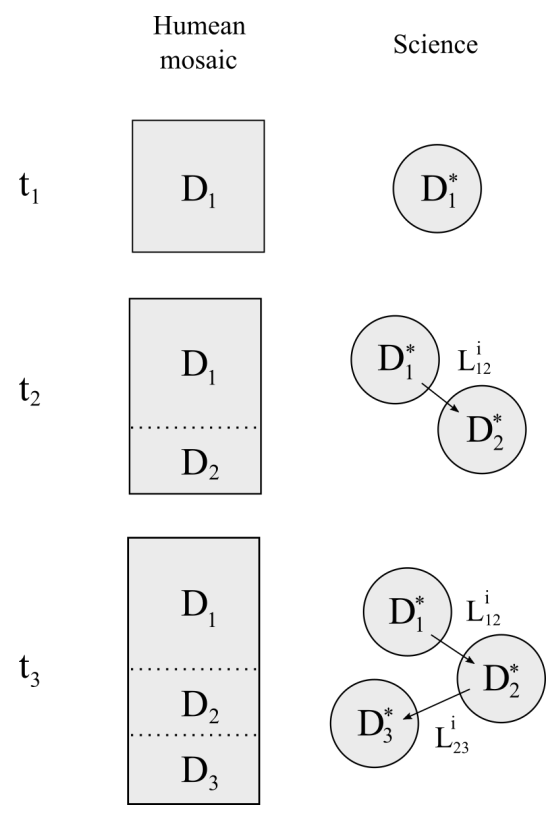

Figure 4: Mill's growing humean mosaic and the science that best systematizes it. Though the domains of events $D_{i}$ are not connected in any ontologically significant way, the associated best deductive systems $D_{i}^{*}$ can all be unified into a single deductive system at any time. This provides a diagrammatical picture of McLaughlin's claim that Millian laws "cluster into systematically related groups" $(1992,63)$.

"On Lewis's account, the laws are immutable, since the laws at each moment are fixed in the same way by the same thing: the universe's complete history of elite-property instantiations. However, Lewis's account entails the laws' immutability only because a certain parameter in the account has been set to 'the universe's entire history'. That parameter could be set differently. For example, there is a deductive system of truths having the best combination of simplicity and informativeness regarding the elite-property instantiations during a given period. I see no grounds on which Lewis's account could object to deeming the members of that system to be the laws during that period".

That Lewis systematically and artificially fixes the laws' starting date to zero is what makes it the case that Mill-style evolutionary emergence cannot occur in his worldview. Unsurprisingly enough, there is no room for 
genuine extensions of the humean mosaic in Lewis' atemporal block universe ontology. For all the fundamental property instances of the mosaic are taken to belong to the unique "elite" domain $D_{1}$ spanning over the whole history of the world, it is no surprise that the laws of the special sciences can enjoy no specific autonomy ${ }^{12}$.

By contrast, and as we've already seen, there is a genuine ontological enforcer of the special sciences' autonomy in Mill's version of the [BSA], namely, the contingent breaches in $[\mathrm{PCC}]$ and, with them, the advent of new domains of the humean mosaic and, correspondingly, of new laws. These are not to be fixed by - nor do they supervene on - "the universe's entire history", a fact which gives Mill flexibility enough, coherently with Lange's words above, to make sense of the set of the world's laws growing through time $^{13}$.

\footnotetext{
${ }^{12}$ That this is true with respect to Mill-style "diachronic" emergence is here doubled by the fact that, according to Lewis, no autonomy for the special sciences is to be found through "synchronic" emergence either, insofar as, according to Lewis himself (1994, 53), "supervenience is reduction". The distinction between diachronic and synchronic varieties of emergence is addressed in section 7. Concerning the impossibility to have diachronic ontological emergence in a block universe ontology, see also Humphreys (2016, 220-227).

${ }^{13}$ Ultimately, that his emergentism can even get off the ground seems to proceed from the fact that Mill implicitly departs from eternalism to embrace (at least some elements of) a growing block universe theory of time. True, it would certainly be vain to claim that Mill actually endorsed an explicit theory of time. Yet, from what has been said so far, it appears that the only available option for Mill is to endorse a kind of mixed view, located somewhere between eternalism and past-presentism. It should indeed be the case that each and every quasi-autonomous domain $D_{i}$ of the mosaic is a self-contained block sub-universe, where nothing new comes into being through time, as therein causes only combine homopathically. It is only through occasional breaches in [PCC] that some new fundamental property instances come into being, when it happens that causes combine heteropathically. Emily Thomas (forthcoming) recently contended that Samuel Alexander, though certainly eternalist, endorsed such a mixed view with regard to some putative cases of emergence (actually the ones related to the quality of deity), and that such leaning towards a growing block universe view certainly inspired Charlie Broad's subsequent philosophy of time, which is usually considered as the ultimate origin of the view (Earman 2008). It is noteworthy that such a mixed view allows for a possible - if perhaps costly reconciliation between humeanism and (elements of) a growing block universe view, reconciliation which is notoriously unstable (see for instance Briggs \& Forbes (2017), where the core of the argument to the effect that humeanism and a growing block view cannot both be true partly rests on the contention that a proposition like "There will be a lunar eclipse on January 21, 2019" is a generic, arbitrary claim. This is certainly false in a Millian set-up, insofar as astronomical laws are paradigmatically homopathic, to the effect that the authors' argument do not generalize to the heteropathic cases, which are the ones that really matter).
} 


\section{Defining humean emergence}

We are now sufficiently equipped to capture the core of Mill's emergence with the help of semi-formal definitions. Formulating such an emergence may be achieved in two equivalent ways, causal and nomic, bearing in mind that, in both cases, what ultimately emerges is a new fundamental property instance of the humean mosaic at a certain time ${ }^{14}$. In line with what has been said so far, an event $E_{j}$ can be said to emerge at time $t_{j}>t_{i}$ as soon as:

\section{[Causal formulation]}

(i) $E_{j}$ is caused by a combination of causes $R\left(c_{i}^{1}, \ldots, c_{i}^{n}\right)$, such that each single $c_{i}^{k}$ in isolation would have caused $e_{j}^{k}$; and

(ii) $E_{j}$ is different from (any) $R^{(*)}\left(e_{j}^{1}, \ldots, e_{j}^{n}\right)$.

\section{[Nomic formulation]}

(i) It is a law that $E_{j}$ regularly follows from $R\left(c_{i}^{1}, \ldots, c_{i}^{n}\right)$, to the effect that $L\left(R\left(c_{i}^{1}, \ldots, c_{i}^{n}\right), E_{j}\right)$ is part of the best system $D^{*}$; and (ii) this law is an ultimate law, to the effect that it is an axiom of the best system $D^{*}$.

Here $E_{j}$ belongs to a domain $D_{j}$, while each $c_{i}^{k}$ and $R\left(c_{i}^{1}, \ldots, c_{i}^{n}\right)$ belong to $D_{i}$. $L\left(R\left(c_{i}^{1}, \ldots, c_{i}^{n}\right), E_{j}\right)$ is a bridge-law connecting $D_{i}$ to $D_{j}$, and it belongs to the best system $D^{*}$, which is either the final best system $\mathcal{D}^{*}$, or the best system $\mathcal{D}_{j}^{*}$ available at $t_{j}$ for systematizing $D_{1} \cup \ldots \cup D_{j-1} \cup D_{j}$.

Both these formulations render explicit what might appear today as an ambiguity in Mill's emergence, which is probably responsible for the fact that two distinct contemporary varieties of emergence, synchronic emergence and diachronic emergence, are both taken to ultimately trace back to Mill's homopathic/heteropathic distinction. In the proposed definitions, there are indeed two possible ways of deciding what the emergence basis of $E_{j}$ actually is.

A first prima facie plausible option in this respect is to consider that the joint effect $E_{j}$ emerges from the set of the "underlying", separate effects $\left\{e_{j}^{k}\right\}$. Such a possible construal of Mill's emergence is commensurate with the traditional holist canon according to which "the whole is more than the

\footnotetext{
${ }^{14}$ Following what has been said in footnote 7 , though it is in line with Mill's own way of talking, the fact that the emergence relation can be construed in causal terms has to be taken with a pinch of salt, as heteropathic combinations of causes are such that, by definition, the condition of unconditionalness fails to hold.
} 
sum of its parts", and seems at first glance congruent with his own example of water being more than hydrogen and oxygen. As such, this first line of thought is in line with the synchronic/holistic tradition of emergentism, according to which emergents are those higher-level units - objects, properties, laws, what have you - that are both dependent on, and autonomous from, underlying, lower-level and simultaneous units, in the spirit of a "layer-cake" ontology of levels of nature, described by a science that has a corresponding stratified structure.

Yet, serious reasons indicate that it is a mistake to construe Mill's emergence in this way. Indeed, as we've seen, there is no way in which one could consider that an emergent joint effect $E_{j}$ synchronically depends on the set of the separate effects $\left\{e_{j}^{k}\right\}$, for in general they are not co-instantiated (it could even be the case that none of the $e_{j}^{k}$ were ever occurrent in the whole history of the universe). Accordingly, and contrary to the present orthodoxy (somewhat ironically) fixed by Kim (see e.g. 1999; or 2006), Mill's emergence is not essentially tied to mereological supervenience, a relation with respect to which the autonomy of emergents is notoriously difficult to come by. Construing Mill's emergence under the canonical, synchronic mold articulated around supervenience would indeed force one to consider - as McLaughlin seems to do $(1992,65)$, although with much precaution - that Mill actually embraced some version of property pluralism and, with it, the existence of higher-level configurational forces. But although it is arguable that subsequent non-humean causal/nomic realists of the synchronic/holistic tradition did embrace the existence of such controversial forces in order to enforce their emergence ascriptions, this is utterly inconsistent with Mill's broadly humean worldview ${ }^{15}$. For one thing, composite entities like water do not "influence" or "modify" the behavior of other entities, among which their own components, simply because, given [RVC], there is nothing in causation that goes beyond mere regularity. Another way to put it is to re-emphasize that Mill's heteropathic laws do not contravene other laws, among which the one about the separate causes and effects, for, given [RVL], when the separate effects do not obtain, there is simply no law "out there" that can be contravened. Equivalently, Mill's heteropathic laws do not "govern" or "regulate" the behavior of underlying or subvening components, for governing and regulating are simply not what humean laws do.

\footnotetext{
${ }^{15}$ As such, Mill's emergence stands in sharp contrast with, say, Samuel Alexander's. Though it is a topic of controversy whether or not Alexander did really believe in nonphysical configurational forces - e.g. McLaughlin (1992) says he did, but Gillett (2006) contends he did not -, what is uncontroversial is that Alexander's position was one of the pioneering steps in the synchronic/holistic tradition of emergence.
} 
This leaves us with the second, more plausible option: $E_{j}$ 's emergence basis, on which it depends and from which it is autonomous, is its antecedent cause $R\left(c_{i}^{1}, \ldots, c_{i}^{n}\right)$. Put differently, in Mill's emergence, the relevant dependence relation is the one that is subsumed under the heteropathic law $L\left(R\left(c_{i}^{1}, \ldots, c_{i}^{n}\right), E_{j}\right)$. Incidentally, the recognition of this fact recently led philosophers to consider Mill as the progenitor, not of the synchronic, but of the dynamical or diachronic tradition of emergence (O'Connor \& Wong 2015; Humphreys 2016). Whether or not Mill himself construed his emergence as involving changes in levels certainly is a subtle matter of exegesis, in which I do not wish to enter here (though, as far as I know, Mill never explicitly subscribed to a "layer-cake" ontology, nor did he ever use the word "level" in his Logic). Still, what seems uncontroversial is that holism is at best parasitic of Mill's emergence, for which the core is, as we've seen, that the humean mosaic happens to grow through time.

The fact that Mill's emergence is best construed as diachronic is of the utmost importance when it comes to the very possibility of reconciling humeanism with emergence. For whether one is inclined to define synchronic emergence on the basis of either (i) supervenience (van Cleve 1990) or, on the contrary, (ii) some failure of supervenience (Loewer 1996), both these options outrightly conflict with mainstream, Lewisian humeanism. In such light indeed, not only does supervenience amount to reducibility (against (i); Lewis 1994), but also the existence of putatively emergent, hence nonsupervenient, things directly conflicts with [HS] (against (ii) $)^{16}$. No issue of this kind plagues diachronic emergentism, for then what ultimately emerges - fundamental property instances - just plainly belong to the humean mosaic. Millian emergents are, as it were, among the very tiles of the mosaic itself - they are to be counted among the world's "perfectly natural properties" (Lewis 1983) -, so the question of how they might possibly relate to such mosaic doesn't even arise. This also accounts for the fact that Millian heteropathic laws do supervene on fundamental property instances of the mosaic - as it should be, given [HS] -, the only difference with conventional humeanism being that, as we've seen, they actually only supervene on a temporal fraction of it ${ }^{17}$.

\footnotetext{
${ }^{16}$ A third option is of course possible: construing emergence through supervenience hence avoiding direct conflict with [HS] -, and supplementing it with an extra ingredient supposed to ensure irreducibility - hence avoiding Lewisian reductionism (see e.g. Kim 1999, where the ingredient is downward causation). However, reasons independent from humeanism usually tend to undermine such a strategy (see e.g. Kim's (2005) own "causal exclusion argument").

${ }^{17}$ It results that Mill's emergence could be classified as diachronic and ontological. Such
} 


\section{Conclusion}

In this paper, I proposed what I consider to be a charitable interpretation of Mill's take on lawhood and emergence. The resulting picture may seem surprising at first glance, as it crystalizes a reconciliation between two metaphysical options that are usually taken to be conflicting, namely humeanism and emergentism. Such reconciliation is nonetheless rendered consistent by taking Mill's dynamical or diachronic construal of emergence seriously, construal which infuses his Best System Account of lawhood by giving it an evolutionary twist. Mill's paradoxical picture of the unity of science is therefore vindicated: special sciences are autonomous from physics in a non-trivial sense - for their laws cannot in principle be deduced from the laws of physics -, yet they can all be unified into a unique, final, and all-encompassing deductive system.

Surely, that humeanism and emergence can peacefully coexist, or that Best System Laws can happen to come into being through time, has only been shown here with the force of logical or metaphysical consistency. At no point did I offer the slightest argument to the effect that such coexistence ought to be desirable (as, for sure, it comes with a price, besides being, as Mill's own illustrations coming from 19th century chemistry and biology indicate, empirically questionable). It then remains to be seen whether the resulting picture can be put to work, something that will have to wait for another time.

an observation, together with the considerations developed in footnote 7, allows for considering Mill's emergence as the humean counterpart of recent accounts of "transformational emergence" (see e.g. Humphreys 2016; or Guay \& Sartenaer 2016; Guay \& Sartenaer 2018). See also Sartenaer (2018) for an exploration of the way in which transformation can slightly deviate from causation. 


\section{References}

[1] Armstrong, D. M. (1983). What is a Law of Nature? Cambridge: Cambridge University Press.

[2] Barnes, E. (2012). Emergence and Fundamentality. Mind, 121(484), 873-901.

[3] Beebee, H. (2000). The Non-Governing Conception of Laws of Nature. Philosophy and Phenomenological Research, 61(3), 571-594.

[4] Briggs, R., \& Forbes, G. A. (2017). The Growing-Block: just one thing after another? Philosophical Studies, 174, 927-943.

[5] Cartwright, N. (1989). Nature's Capacities and their Measurement. New York: Oxford University Press.

[6] Cohen, J., \& Callender, C. (2009). A Better Best System Account of Lawhood. Philosophical Studies, 145(1), 1-34.

[7] Earman, J. (1986). A Primer on Determinism. Dordrecht: D. Reidel.

[8] Earman, J. (2008). Reassessing the Prospects for a Growing Block Model of the Universe. International Studies in the Philosophy of Science, 22(2), 135-164.

[9] Elder-Vass, D. (2010). The Causal Power of Social Structures. Emergence, Structure and Agency. Cambridge: Cambridge University Press.

[10] Gillett, C. (2006). Samuel Alexander's Emergentism. Synthese, 153(2), 261-296.

[11] Gillett, C. (2016). Reduction and Emergence in Science and Philosophy. Cambridge: Cambridge University Press.

[12] Guay, A., \& Sartenaer, O. (2016). A New Look at Emergence. Or When After is Different. European Journal for Philosophy of Science, $6(2), 297-322$.

[13] Guay, A., \& Sartenaer, O. (forthcoming). Emergent Quasiparticles. Or How to Get a Rich Physics from a Sober Metaphysics. In O. Bueno, M. Fagan, \& R.-L. Chen (Eds.), Individuation, Process and Scientific Practices. New York: Oxford University Press. 
[14] Humphreys, P. W. (1997). How Properties Emerge. Philosophy of Science, 64(1), 1-17.

[15] Humphreys, P. W. (2016). Emergence. A Philosophical Account. New York: Oxford University Press.

[16] Kim, J. (1992). "Downward Causation" in Emergentism and Nonreductive Physicalism. In A. Beckermann, H. Flohr, \& J. Kim (Eds.), Emergence or Reduction? Essays on the Prospects of Nonreductive Physicalism (pp. 119-138). Berlin: De Gruyter.

[17] Kim, J. (1999). Making Sense of Emergence. Philosophical Studies, 95(1-2), 3-36.

[18] Kim, J. (2005). Physicalism, or Something Near Enough. Princeton: Princeton University Press.

[19] Kim, J. (2006). Emergence: Core Ideas and Issues. Synthese, 151(3), 547-559.

[20] Lange, M. (2008). Could the Laws of Nature Change? Philosophy of Science, 75, 69-92.

[21] Lewis, D. (1983). New Work for a Theory of Universals. Australasian Journal of Philosophy, 61(4), 343-377.

[22] Lewis, D. (1986). Philosophical Papers (Vol. II). Oxford: Oxford University Press.

[23] Lewis, D. (1994). Reduction of Mind. In S. Guttenplan (Ed.), A Companion to Philosophy of Mind (pp. 412-431). Oxford: Blackwell Publishers.

[24] Loewer, B. M. (1996). Humean Supervenience. Philosophical Topics, 24, 101-127.

[25] Lowe, E. J. (2008). Personal Agency. The Metaphysics of Mind and Action. Oxford: Oxford University Press.

[26] Macleod, C. (2017). John Stuart Mill. In Zalta, E.N. (Ed.), The Stanford Encyclopedia of Philosophy. URL: https://plato.stanford.edu/archives/spr2017/entries/mill/. 
[27] McLaughlin, B. P. (1992). The Rise and Fall of British Emergentism. In A. Beckermann, H. Flohr, \& J. Kim (Eds.), Emergence or Reduction? Essays on the Prospects of Nonreductive Physicalism (pp. 49-93). Berlin: de Gruyter.

[28] Mill, J. S. (1884). A System of Logic, Ratiocinative and Inductive, Being a Connected View of the Principles of Evidence and the Methods of Scientific Investigation. London: Longmans, Green, and co.

[29] Millgram, E. (2009). John Stuart Mill, Determinism, and the Problem of Induction. Australasian Journal of Philosophy, 87(2), 183-199.

[30] O'Connor, T., \& Wong, H. Y (2015). Emergent Properties. In Zalta, E. N. (Ed.), The Stanford Encyclopedia of Philosophy. URL: https://plato.stanford.edu/archives/sum2015/entries/propertiesemergent/

[31] Peacocke, A. (2007). Emergent Realities with Causal Efficacy: Some Philosophical and Theological Applications. In N. C. Murphy \& W. R. Stoeger (Eds.), Evolution and Emergence: Systems, Organisms, Persons (pp. 267-283). New York: Oxford University Press.

[32] Psillos, S. (2002). Causation and Explanation. Chesham: Acumen Publishing Limited.

[33] Sartenaer, O. (2018). Flat Emergence. Pacific Philosophical Quarterly, 99, 225-250.

[34] Schmidt-Petri, C. (2008). Cartwright and Mill on Tendencies and Capacities. In S. Hartmann, C. Hoefer, \& L. Bovens (Eds.), Nancy Cartwright's Philosophy of Science (pp. 291-304). New York: Routledge.

[35] Schrenk, M. (2008). A Theory for Special Sciences Laws. In H. Bohse, K. Dreimann, \& S. Walter (Eds.), Selected Papers Contributed to the Sections of GAP.6, 6th International Congress of the Society for Analytical Philosophy. Paderborn/Munster: Mentis.

[36] Schrenk, M. (2017). The Emergence of Better Best System Laws. Journal for General Philosophy of Science, 48(3), 469-483.

[37] Stephan, A. (1992). Emergence - A Systematic View on its Historical Facets. In A. Beckermann, H. Flohr, \& J. Kim (Eds.), Emergence or Reduction? Essays on the Prospects of Nonreductive Physicalism (pp. 25-48). Berlin: de Gruyter. 
[38] Thomas, E. (forthcoming). The Roots of C.D. Broad's Growing Block Theory of Time. Mind.

[39] Tooley, M. (1977). The Nature of Laws. Canadian Journal of Philosophy, 7(4), 667-698.

[40] van Cleve, J. (1990). Mind-dust or magic? Panpsychism versus emergence. Philosophical Perspectives, 4, 215-226.

[41] Wilson, J. (2015). Metaphysical Emergence: Weak and Strong. In T. Bigaj, \& C. Wurthrich (Eds.), Metaphysics in Contemporary Physics (pp. 251-306). Leiden: Brill. 